OPEN ACCESS

Edited by:

Afsaneh Moradi,

Maastricht University, Netherlands

Reviewed by:

Robert Cowley,

King's College London,

United Kingdom

Miguel Valdez,

The Open University, United Kingdom

*Correspondence:

Caterina Cavicch

caterina.cavicchi@unife.it

Specialty section:

This article was submitted to

Governance and Cities,

a section of the journal

Frontiers in Sustainable Cities

Received: 05 February 2021

Accepted: 25 May 2021

Published: 18 June 2021

Citation:

Cavicchi C (2021) Higher Education and the Sustainable Knowledge Society: Investigating Students

Perceptions of the Acquisition of

Sustainable Development

Competences.

Front. Sustain. Cities 3:664505 doi: 10.3389/frsc.2021.664505

\section{Higher Education and the} Sustainable Knowledge Society: Investigating Students' Perceptions of the Acquisition of Sustainable Development Competences

\author{
Caterina Cavicchi* \\ Department of Economics and Management, University of Ferrara, Ferrara, Italy
}

The application of a constructivist approach to competence-based frameworks for sustainable development (SD) in higher education can empower students to become change agents. Acknowledging this development, this paper examines the extent to which an SD-directed master's programme at an Italian university effectively developed students' SD competences before and during the COVID-19 pandemic. The study is based on a mixed method approach that includes a survey and interviews in order to (a) discuss students' experiences with pedagogies that emphasize SD competences as learning outcomes and (b) analyze students' perceptions of acquiring SD competences with reference to their experience of internships, project work, and job positions (in the case of graduates). The results show that, among the analyzed SD pedagogies, case studies were perceived to enrich students' understanding of the complexity of SD issues through collective learning. However, to develop critical thinking, students recognized the need to customize the case studies' plots. Regarding practical SD activities, internships, and project work were perceived as opportunities to network with stakeholders and to develop problem-solving abilities. The pandemic significantly decreased the use of such SD pedagogies, thereby prioritizing self-directed learning and research-based internships. Despite the increase in e-learning events involving stakeholders, the prospect of interacting with them on SD topics was hampered by the limitations of information technology support. Nevertheless, the students' perceptions of the effectiveness of teaching and learning processes provide recommendations to improve the SD pedagogies and e-learning adopted by higher education institutions (HEls).

Keywords: higher education, sustainable development competences, constructivism, pedagogies, virtual setting, COVID-19

\section{INTRODUCTION}

This section reviews the teaching approaches that focus on sustainable development (SD) competences as learning outcomes and facilitates the discussion of the constructivist approach to sustainability education, considering that constructivism is a promising teaching approach that aims to develop students' SD competences through collective SD-related learning processes and 
practical tasks. The literature review outlines and justifies the investigation of students' perceptions of the effectiveness of these SD pedagogies, as explored by the study presented in this paper.

Higher education institutions (HEIs) play a major role in the transition to a sustainable knowledge society (O'Riordan et al., 2020). To achieve this goal, the literature favors the need for HEIs to implement new pedagogies that provide students with learning outcomes (Shephard, 2008; Gatti et al., 2019), leading to the emergence of action learning-based teaching approaches that stimulate students' motivation and critical thinking on SD, and that promote the transmission of SD competences (Gatti et al., 2019; Wilhelm et al., 2019). The resulting research includes the proposal of new approaches to and methods of teaching that focus on competence development (Roorda, 2010; Lambrechts et al., 2013; Molderez and Fonseca, 2018), on the comparison of different teaching approaches to determine their efficacy in developing SD competences, and on methods that instill higher education curricula with the development of SD competences. However, the debate remains fragmented and is seldom based on sound pedagogic foundations (Cebrián and Junyent, 2015; Wilhelm et al., 2019). To facilitate the development of SD competences, Barth and Burandt (2013) justify the need to shift "from teacher- to learner-centered pedagogies, from input- to output-orientation and from a focus on content to problemsolving and process-orientation" (p. 2611). These pedagogies enable students to become "agents of change" (De Kraker et al., 2007; Lansu et al., 2010; Wilhelm et al., 2019).

Several higher education, SD competence-based frameworks have been proposed over time. For instance, Wiek et al. (2015) define SD competences as "a functionally linked complex of knowledge, skills, and attitudes that enable successful task performance and problem-solving with respect to real-world sustainability problems, challenges and opportunities" (Wiek et al., 2011, p. 204). Drawing on an extensive literature review and acknowledging the need to address competences as learning outcomes, they propose the development of a consolidated and integrated set of competences at novice, intermediate, and advanced levels within HEI programmes. In their proposed framework, SD competences include system thinking, anticipatory, normative, strategic, and interpersonal competences, and the capacity to combine these key abilities to solve complex sustainability problems and to foster SD transition (Wiek et al., 2015). Lambrechts and Van Petegem (2016) focus on the importance of research competences, asserting that these "research competences are necessary in order to contribute to handling SD issues, while competences oriented toward attitudes are contributing to the acquisition of values and attitudes inherent to SD" (p. 16). Lambrechts et al. (2018) emphasize the need for learning paths that are customized based on attitudes of students and on their willingness to apply sustainable lifestyles, and call for approaches that prepare students to face the complexity of sustainability. These approaches are oriented toward self-regulated learning in combination with the development of critical and interpretational competences. Ploum et al. (2018) validate a set of competences to support sustainable entrepreneurship.
Pérez Salgado et al. (2018), based on Mochizuki and Fadeeva (2010), argue that the tendency of SD competences to attain meaning dependent on their application context and practice, undermines any attempt at a universal definition. On the contrary, competences in educational programs are often decontextualized from practice (Ploum et al., 2018). As a result, there has been a proliferation and diffusion of approaches that are grounded in the definition of competences in interaction with SD professionals and in the testing of these competences in different, discipline-based HEI programs (Pérez Salgado et al., 2018). The need to consider competences in the context of their application aligns with constructivist thought (Pérez Salgado et al., 2018). Constructivism in higher education is based on the ideas that learning (a) is a process of interaction between what is known (previous experience) and what is to be learned; (b) is a social process as knowledge is constructed through interactions with other individuals; (c) is situational as it is affected by social and cultural circumstances; (d) is a metacognitive process as it is based on the possibility to develop problem-solving skills and to use these skills to learn effectively; and (e) is based on students' autonomy (Bognar et al., 2016; Vintere, 2018).

Examples of the constructivist approach's application in pedagogies that favor the development of SD competences are found in De Kraker et al. (2007) who introduced the concept of transboundary competence. Transboundary competence includes "the abilities to take a whole systemsoriented, interdisciplinary, participatory or transdisciplinary, international, cross-cultural, cross-scale, future-oriented, and creative approach to sustainability problems" (De Kraker et al., 2007, p. 108). The development of this competence requires a pluralistic approach and interaction with stakeholders (Lansu et al., 2010). This requirement, in turn, allows the development of SD strategies through negotiation and participation processes in heterogeneous groups (De Kraker et al., 2007). Students' acquisition of this competence can be assessed by analyzing their personal reflections on learning experiences, developed along their academic paths (De Kraker et al., 2007). The transboundary competence is complemented by intervention competence (Pérez Salgado et al., 2012, 2014, 2018); a concept that denotes problem-solving abilities. In the context of climate change, for example, intervention competence is defined as "politicalstrategic thinking, combined with personal and individual goaldirectedness, appreciating the importance of networking or the professional labor market, and paying attention to policy assessments and policy scenarios in climate change issues" (Pérez Salgado et al., 2012, p. 53).

More recent studies based on the constructivist approach to the development of SD competences include those of Vintere (2018), Wilhelm et al. (2019), and Dziubaniuk and Nyholm (2020). Vintere (2018), analyzing the perceptions of mathematics students on SD competence development, favors a constructivist approach that links teaching and learning to everyday life; a condition which is met when students learn in interaction with others, learn to apply knowledge in real-life situations, are motivated by an understanding of how to use this knowledge in a future profession, and are encouraged to engage with self-directed learning (Vintere, 2018). Wilhelm et al. (2019) 
emphasize pedagogies that initiate personal change (Wilhelm et al., 2019). In this sense, the emphasis is on the need to create space for the personal dimensions of competences (values, attitudes, and lived experiences, i.e., socio-emotional and behavioral competences), to complement systemic competences (cognitive competences related to the development of objective knowledge applicable to decision making), and to promote the transition to SD (Dlouhá et al., 2019).

Wilhelm et al. (2019), based on Le Boterf (2015), also argue that competences cannot be transmitted but that they must be assessed in terms of students' performances, thus considering the achievement of a task in a specific situation. Therefore, when integrating a competence-based orientation into teaching and learning, it is necessary to define the future context in which knowledge, attitudes, and skills are required, and to determine the kind of problems and the context in respect of which the student must perform. Constructive alignment with the design of learning outcomes is deemed promising and should focus on the extent to which (a) teaching and learning activities foster learning outcomes, (b) the educational environment allows students to become change agents, and (c) the assessment methods provide knowledge on the attainment of learning outcomes (Wilhelm et al., 2019). Dziubaniuk and Nyholm (2020), after analyzing the teaching of SD and business ethics in a business school and focusing on students' course feedback, found that students' participation in seminars and group work on creative assignments enhanced their development of critical thinking and incentivized collective learning. Increased motivation, thanks to course activities, also reflected in positive sustainability behaviors that students exhibited in their personal lives. In addition, the students perceived learning by-doing through personal assignments as a way of approaching sustainability in practical terms. Irrespective, the students acknowledged the need for more discussion during conventional lectures, specifically to further their active role in knowledge co-creation.

Dziubaniuk and Nyholm (2020) also encourage exploratory research on the suitability of pedagogical approaches that teach sustainability from both a quantitative and a qualitative perspective, and on the efficacy of these approaches in the light of the COVID-19 pandemic as it may have affected the provision of teaching and learning opportunities. Since studies on pedagogies' effect on the acquisition and implementation of SD competences are still limited (Tejedor et al., 2019), more research is also required on the use of these pedagogies in different contexts, so as to shed light on didactic approaches that HEIs could adopt to enable students becoming change agents (Lozano et al., 2019).

The present paper aims to fill this gap by analyzing the case of a North Italian university that had recently reoriented its Master's Programme in Economics and Management toward SD. A questionnaire was prepared and sent to a sample of students enrolled for this SD-focused master's programme over time (hereinafter the Master's Programme), in order to analyze their perceptions of the acquisition of SD competences. This analysis of the students' perceptions focuses on:

- internships and/or project work students did in terms of the university's agreements with private entities, non-profit organizations, and local institutions, to deal with practical SD-related issues; and

- current job experience (of graduates) to investigate their use of SD competences obtained and matured during their academic careers, professional development, and active-citizenship, thus contributing to a sustainable knowledge society.

In addition, the survey also covers the extent to which the new pedagogies (De Kraker et al., 2007; Cörvers et al., 2016; Dziubaniuk and Nyholm, 2020) directed at SD competences were applied at the university, both before and after the outbreak of the COVID-19 pandemic. Because the pandemic favored the transition of HEI activities to virtual platforms, this paper investigates if the use of e-learning similarly favors the adoption of new SD pedagogies.

In order to provide a more detailed account of the students' perceptions of the acquisition of SD competences and to acquire information on their application of these competences in specific tasks and projects, a series of interviews were conducted with 11 students who participated in SD internships or who occupied sustainability related job positions at the time of the survey.

The paper is structured as follows: section 2 reviews the concept of sustainability competences as SD learning outcomes and discusses the role of new pedagogies for SD; section 3 clarifies the research methodology; section 4 presents the research results; and section 5 provides a discussion of the study's findings and conclusions.

\section{NEW SD PEDAGOGIES IN HIGHER EDUCATION}

The development of frameworks based on SD competencesdiscussed in the previous section-was accompanied over time by experimentation with new pedagogies. Based on an extensive literature review with a focus on the constructivist approach to sustainability teaching, this section discusses proposed pedagogies that reorient higher education toward $\mathrm{SD}$. In conclusion, it deepens the role of on-line teaching through a major recommendation that incorporates the impact of the COVID-19 pandemic on the use of e-learning and SD pedagogies.

Various didactic strategies based on a constructivist approach have been proposed to foster SD competences. These strategies align with international guidelines on education for SD and therefore include problem and project-based learning, service learning, and case studies (Tejedor et al., 2019). Lozano et al. (2017) reviewed different higher education pedagogical approaches and correlated them with SD competences in order to determine their effect on the development of these competences. The identified approaches and methods include the following:

- Universal approaches, common to various disciplines and contexts, which include widely used methods such as case studies, inter-disciplinary team teaching, lecturing, cognitive and conceptual maps, and project or problem-based learning.

- Community and social justice approaches, which address social justice and community building, and which 
include methods such as community service learning, jigsaw/interlinked teams, and participatory action research.

- Environmental education, which refers to pedagogies developed in environmental sciences or are derived from environmental practices, and which includes methods such as eco-justice and community, place-based environmental education, supply-chain/life-cycle analysis, and traditional ecological knowledge.

Based on their extensive literature survey and analysis of competences, Lozano et al. (2017) identified the following set of 12 SD competences: system thinking, interdisciplinary work, anticipatory thinking, justice, responsibility and ethics, critical thinking and analysis, interpersonal relations and collaboration, empathy and a change of perspective, communication and use of media, strategic action, personal involvement, assessment and evaluation, and tolerance of ambiguity and uncertainty. They argue that no single pedagogical approach can cover all of the competences that students must develop, although combinations of pedagogies-based on education, eco-justice, case studies, and jigsaw/interlocked teams-could provide the majority of $\mathrm{SD}$ competences. The authors furthermore proposed the testing of pedagogies to determine the extent to which they provide students with these competences. Through further testing, they showed that case studies and project/problem-based learning were the most-used approaches to deal with SD. However, the correlation of pedagogical approaches and competences revealed that case studies may not be a suitable pedagogy to develop certain SD competences, such as justice, responsibility and ethics, and tolerance of ambiguity and uncertainty. On the contrary, pedagogies based on eco-justice education, project and problembased learning, community service learning, interdisciplinary learning, cognitive and conceptual maps, and jigsaw and placebased environmental education were deemed the most likely approaches to develop SD competences.

After examining the literature on management education, Figueiró and Raufflet (2015) identified several teaching strategies that can be applied to SD. Some of these strategies include methodologies such as the case-study method, action and experiential learning, service learning, and problem-based learning, whereas others include games, debates, seminars, etc. Among these pedagogies, real-world case studies and service learning were specifically identified as approaches that can develop students' SD competences (Molderez and Fonseca, 2018). First, case studies of real-world situations favor decision making on complex SD issues, due to the interaction they allow with stakeholders, and they also favor interpersonal competences and enhance emotions that can sustain personal development. Second, since service learning activities are educational paths that are based on the convergence of community needs, they can enhance systemic thinking and personal engagement in the SD-transition process.

An emerging research field, based on students' perceptions, tries to determine if these approaches are functional to SD-competence development. For instance, by focusing on case studies and on the implementation of an active learning, constructivist approach, Kalamas Hedden et al.
(2017) contend that multi-disciplinary case studies-in the form of project-based initiatives that allow interaction with stakeholders - can promote sustainable education. Through this active learning, constructivist approach, students can become lifelong learners and develop critical thinking and problemsolving skills that would allow them to deal with real-world sustainability challenges.

Based on Wiek et al.'s (2011) framework of SD competences, Molderez and Fonseca (2018) analyzed students' perceptions of the effectiveness of pedagogies in the economic and business education disciplines. They found that even though students had developed various levels of SD abilities, based on their experiences, they did not link the application of these competences to their future professional careers. This premise suggests that attempts to experiment with new pedagogies produced mixed results, thus requiring additional and more incisive investigation.

By focusing on the development of transboundary competence as a learning outcome of academic curricula, scholars also discussed the potential of teaching methods based on ill-structured problems or case studies related to sustainability, which require the integration of knowledge derived from different domains, different scales of space and time, and creative solutions to problems (De Kraker et al., 2007). To develop this competence, a pluralistic approach and interaction with stakeholders are essential (Lansu et al., 2010), including negotiation and participation processes to develop SD strategies in heterogeneous groups. Such abilities can be assessed through students' personal and collective reflections on the learning experiences they accessed along their academic paths (De Kraker et al., 2007). With reference to climate change education in academic programmes, Wilson et al. (2011) underlined the need for an expanded conceptualization of the interdisciplinary approach that integrates academic disciplinary knowledge with lived experience. Accordingly, the interdisciplinary approach is not only seen as a means to integrate different disciplines, but also as a means to integrate the different viewpoints of students, citizens, and professionals by creating learning communities and virtual mobility settings. Therefore, new pedagogies should focus on competences that can be applied in personal and professional life and should meet the professional requirements of stakeholders (Pérez Salgado et al., 2012; Lansu et al., 2013).

E-learning occupies a prominent position in the proposed approaches that favor the development of learning communities and their transition toward a more sustainable society. Based on an extensive review of online education and as argued by Azeiteiro et al. (2015), the use of e-learning has several advantages, including flexibility, collaborative learning, and critical thinking, the formation of learning communities, and learning outcomes comparable to those of face-to-face courses. Regarding online SD education, students' perceptions have been investigated to determine the effectiveness of the adopted pedagogies and, above all, their value as harbingers of SD competences and active citizenship. In study Azeiteiro, Bacelar-Nicolau, Caetano and Caeiro (2015), students awarded higher acceptability ratings to pedagogical methods, tools, and 
resources based on Moodle ${ }^{1}$ lessons, bibliographic resources, and teachers' support texts, while they perceived slides and videos to be less effective. Despite students' recognition of the acquisition-through the investigated pedagogies-of learning outcomes involving attitudes, behavior, competences, environmental citizenship, and participation at various levels, the authors nevertheless concluded that the new pedagogies should focus more on skill application in real-world contexts. Therefore, they proposed audiovisuals, communication tools, and problembased learning as effective ways to enhance sustainability literacy through interaction.

To this end and by focusing on the individual's learning environment, scholars discussed the features of an e-learning environment that could produce SD competences. This endeavor was aligned to the required constructivist approach, based on three principles: self-directed learning, collaborative learning, and problem-oriented learning (Barth and Burandt, 2013). Respectively, self-directed learning focuses on the autonomous construction of knowledge; collaborative learning on collaboration that allows the development of individual and collective knowledge on the basis of shared experiences and learning objectives; and problem-oriented learning on the development of action competences through creative solutions to real-world problems (Barth and Burandt, 2013). Scholars also identified virtual mobility settings, seminars, and remote internships as promising approaches to SD education because they allow students to cross geographical boundaries and to interact in ways that enhance their personal and professional development.

Pérez Salgado et al. (2012) reported experiences with a Master of Lived Experience on Climate Change. The students were required, first, to develop a vision on climate change issues, being aware of different perspectives derived from divergent geographical, cultural, social, and economic contexts and, second, to integrate natural and scientific knowledge with a lived experience on climate change. Transboundary and intervention competences can develop to this end, owing to the establishment of the aforesaid learning communities and the use of virtual settings. Barth and Burandt (2013) reported on three HEI case studies where the SD e-learning environment produced major benefits that were ascribed to an increase in students' intercultural awareness, the facilitation of interdisciplinary communication, and the generation of shared knowledge. These benefits strengthened students' learning processes and facilitated their project management. Lansu et al. (2010) discussed the experience of remote internships where students engaged in teamwork on sustainability research questions, on behalf of companies and organizations that became "clients" of the university. By interacting with their peers, the company's mentors, and the university's tutors, students were empowered to produce and present consultancy advice reports. As a result, the learning network became a means through which they developed and applied a transboundary competence in their personal and professional practices. The combined use of

\footnotetext{
${ }^{1}$ Moodle is an open-source e-learning platform that supports HEIs in creating personalized learning environments for online teaching.
}

digital technologies for global collaboration among universities and local learning experiences was seen as a valuable teaching approach that favors students' development as active citizens; citizens who apply sustainability competences ranging from local to global scales (Caniglia et al., 2018).

During the COVID-19 pandemic, many HEIs around the world faced the need to move their activities to online platforms, thereby creating space for a plurality of reorganization strategies (Crawford et al., 2020). Based on the previously discussed premises, e-learning provides an opportunity in the SD field to facilitate the interactions of different actors, including students, experts, teachers, and stakeholders in different institutional contexts, thus creating a unique learning community in which $\mathrm{SD}$ competences can be applied in practice. In this context, the paper investigates the extent to which an e-learning environment, in particular during the COVID-19 pandemic, provides an opportunity to strengthen the use of new SD pedagogies. More specifically, the paper examines and compares the extent to which new SD pedagogies were applied before and after the pandemic's advent.

\section{MATERIALS AND METHODS}

The investigated setting is a North Italian university where a Master's Programme in Economics and Management was introduced, with a focus on the development of managerial SD competences. This university was chosen as the subject of inquiry because, over the past years, it has been engaged in a reorientation of its academic programs toward SD. In addition, the university is well known for its sustainability engagement through various initiatives ranging from its participation in international SD-performance measurement rankings, through SD-related teaching and research activities, to the reporting of initiatives. The reorientation of education toward sustainability occurred, among others, in the university's Department of Economics and Management that presents the particular academic programme. The Master's Programme was launched in the 2015-2016 academic year. The aim of the programme is to prepare and qualify students for managerial or consultancy positions in the green economy and sustainability sector. The SD competences that students can develop are specified in the programme's overview, which is made available to them at enrollment. These competences include an impact analysis of international and national SD policies on markets and businesses; sustainability performance management in public and private organizations; the management of ecoinnovation; and an economic impact analysis of the use of natural resources.

The sample comprised 545 students and included students enrolled in and/or graduated from the program. A purposive sampling technique, namely the maximum variation sampling technique was used since it allows the emergence of the variability of students' perceptions of the development of SD competences during and after their academic careers (Etikan et al., 2016). A questionnaire-based survey was conducted (Moser and Kalton, 2017) to determine the extent to which this SD-directed 
programme effectively enhanced the students' SD competences. The questionnaire was subdivided into the four sections:

- The students' employment status at the time of the survey (section 1).

- The new pedagogical approach and its effective use to develop sustainability competences (section 2).

- The internships/project work students participated in under the university's agreement with private entities, non-profit organizations, and local institutions, to deal with practical issues related to $\mathrm{SD}$ (section 3).

- The work-related experiences (of graduates) to determine the extent to which they used mature SD competences in their academic careers, personal and professional development, and active-citizenship, thus contributing to a sustainable knowledge society (section 4).

Regarding section 2, the survey focused on innovative pedagogies to develop and apply SD competences (De Kraker et al., 2007; Cörvers et al., 2016; Tejedor et al., 2019; Dziubaniuk and Nyholm, 2020), and on the extent to which these pedagogies allow students to develop and mature a multiscale (local to global), interdisciplinary, multi-stakeholder, and long-term oriented vision. In particular, respondents were asked to identify if and to what extent they applied innovative pedagogies.

To determine the impact of these pedagogies on teaching, the survey distinguished between the periods before and after the declaration of the pandemic emergency in accordance with the Prime Minister Decree of March 9th, 2020. In Italy, this date marked the beginning of the pandemic emergency (hereinafter the COVID-19 emergency). This distinction was made in section 2 of the questionnaire by asking students if they attended SD courses before or after the declaration of the COVID-19 emergency. It allows a determination of whether the e-learning education implemented after the decreed emergency significantly changed the education approaches to and the students perceptions of the development of $\mathrm{SD}$ competences.

In respect of sections 3 and 4 of the questionnaire and based on the literature (Pérez Salgado et al., 2012, 2018), the questions were formulated to verify the extent to which the SD-projects' internships and work experience allowed the respondents to:

- take part in interdisciplinary projects requiring the integration of different approaches derived from the natural and social sciences,

- develop an awareness of the different perspectives of the stakeholders involved in SD projects,

- identify problems related to the management of SD issues,

- propose solutions to SD problems, owing to their development of networking abilities with institutional and entrepreneurial organizations,

- improve their understanding of SD policies promoted at the institutional level, as well as of the possible impact of these policies on and the scenarios they generate in the local context,

- combine their personal and professional development with active citizenship favoring SD.
In addition, questions were asked to determine if the respondents, in the implementation of SD projects, were able to apply:

- their personal experience;

- the mature competences developed during their academic careers.

The respondents were required to rate their perceptions on a 5-point Likert Scale. With regard to pedagogies, students were asked to rate the extent to which they experienced SD pedagogies and follow-up sessions ( 1 corresponds with "never" and 5 with "always"). With regard to SD internships and project work, students were asked to rate the extent to which they developed SD competences as a result of these practical activities ( 1 corresponds with "not at all" and 5 with "extremely").

The survey, developed with Qualtrics software, was sent out in October 2020 and was closed in April 2021. Periodical recalls were used to increase the response rate.

Regarding the discussion of the survey results, descriptive statistics are provided for sections 2, 3, and 4 of the questionnaire. In addition, the section 2 analysis includes the differences in the application of SD pedagogies during the periods before and after the declaration of the COVID-19 emergency. To conduct this analysis the total sample was divided into two samples, respectively, based on the respondents' indication of their attendance of SD courses before or after the declaration of the COVID-19 emergency. These differences were tested through the Mann-Whitney U Test for non-parametric data (Field, 2009). The Mann-Whitney U Test was chosen as the two samples were different in size and included ordinal scale observations. The Mann-Whitney test of the null hypothesis makes provision to draw the two samples from a single population, whilst the alternative hypothesis is that one of the two samples is stochastically larger. The "rule of thumb" for the test is that when the $p$-value is $<0.05$, there is a meaningful difference between the two samples.

Given the small sample size of students who experienced an SD-oriented internship or job activity, it was not possible to test for the differences between students' acquisition of SD competences before and after the declaration of the COVID-19 emergency. Thus, the questionnaire's analysis was supplemented by interviews conducted with 11 students. The selection of the interviewees was based on their involvement in SD related internships and job positions, as the literature recommends the assessment of students' acquisition of SD competences through practical performance (Wilhelm et al., 2019). In total, 21 students indicated that they participated in an internship or held an SD-related job position, of whom 11 agreed to be interviewed. Table 1 provides the details of the sample.

The purpose of the interviews was to determine the extent to which students perceived to have acquired SD competences due to new pedagogies which not only stimulate the emergence and development of these competences (Lozano et al., 2019), but which also promote their application in practical and active citizenship' projects. In addition, students were asked to indicate their perception of the changes in the university teaching 
TABLE 1 | The characteristics of the interviewees.

\begin{tabular}{|c|c|c|}
\hline & Actual position & Field of interest/activity \\
\hline Interviewee 1 (I1) & Researcher & $\begin{array}{l}\text { Research in environmental } \\
\text { economics, emissions, and green } \\
\text { finance }\end{array}$ \\
\hline \multirow[t]{2}{*}{ Interviewee 2 (I2) } & Researcher & $\begin{array}{l}\text { Research on immigration and social } \\
\text { sustainability }\end{array}$ \\
\hline & & $\begin{array}{l}\text { Internship during the academic path } \\
\text { related to the development of } \\
\text { sustainability reporting in a cosmetic } \\
\text { firm }\end{array}$ \\
\hline Interviewee 3 (I3) & Researcher & $\begin{array}{l}\text { Research on projects related to } \\
\text { environmental conservation aimed at } \\
\text { understanding people's willingness to } \\
\text { pay for a reduction of the loss of } \\
\text { biodiversity }\end{array}$ \\
\hline Interviewee 4 (14) & Researcher & $\begin{array}{l}\text { Research focused on monitoring the } \\
\text { antimicrobial resistance of an } \\
\text { agro-ecosystem }\end{array}$ \\
\hline Interviewee 5 (15) & Graduate & $\begin{array}{l}\text { Internship in waste management: } \\
\text { development of a punctual pricing } \\
\text { system for municipal waste } \\
\text { management }\end{array}$ \\
\hline Interviewee 6 (16) & Working student & $\begin{array}{l}\text { Job tasks related to sustainable } \\
\text { agri-food chain management }\end{array}$ \\
\hline Interviewee 7 (I7) & Full time student & $\begin{array}{l}\text { Internship linked to the forest } \\
\text { management of a river bed and to the } \\
\text { recovery of woody debris, in terms of } \\
\text { a perspective of circular economy } \\
\text { innovation }\end{array}$ \\
\hline Interviewee 8 (I8) & Full time student & $\begin{array}{l}\text { Research-focused internship: the } \\
\text { internship was aimed at investigating } \\
\text { eco-innovation in businesses }\end{array}$ \\
\hline Interviewee 9 (19) & Consultant & $\begin{array}{l}\text { Job tasks related to non-financial and } \\
\text { sustainability reporting in companies }\end{array}$ \\
\hline Interviewee 10 (110 & ) Full time student & $\begin{array}{l}\text { Research focused internship: the } \\
\text { internship was aimed at deepening } \\
\text { the relation between public } \\
\text { expenditures and greenhouse gas } \\
\text { emissions }\end{array}$ \\
\hline \multirow[t]{2}{*}{ Interviewee 11 (111) } & ) Graduate & $\begin{array}{l}\text { Job tasks related to sustainable } \\
\text { suppliers' selection in a clothing } \\
\text { company }\end{array}$ \\
\hline & & $\begin{array}{l}\text { Internship during the academic path } \\
\text { on the management of sustainable } \\
\text { cities }\end{array}$ \\
\hline
\end{tabular}

strategies after the declaration of the COVID-19 emergency. Furthermore, the use of the virtual learning setting was examined during the interviews in order to determine if the teaching change impacted on the acquisition of competences.

The interview protocol included the following topics:

- Students' experience of SD-focused pedagogies (case studies, role playing, and projects).

- The impact of distance learning (implemented due to the pandemic) on the use of SD pedagogies.

- Sustainable development competences developed by students as a consequence of these pedagogies, internships, project work, and personal experience.
- Sustainable development competences applied in actual and anticipated job position.

- Active citizenship for sustainability developed on account of students' personal experience and acquisition of $\mathrm{SD}$ competences.

The interviews were recorded with permission and were transcribed in nine of the 11 cases; for the remaining two interviews, the recording impediment was circumvented by using field notes. Each interview lasted between 30 and $40 \mathrm{~min}$. The interviews (transcripts and field notes) were manually contentanalyzed to identify common and divergent patterns, based on deductive reasoning (Eisenhardt, 1989). Afterward, to triangulate the findings, they were crossed with survey data (Eisenhardt, 1989).

\section{RESULTS}

The survey response rate was approximately $24 \%$. After the screening process 129 questionnaires were regarded as completed, thus representing the final sample for the analysis. This sample comprised 84 full-time students, 22 working students, 10 graduates who were employed at the time of the survey, 7 graduates who were unemployed at the time of the survey, 3 (graduating) students who had to defend their master's thesis, and 3 Ph.D. students. The reported survey (Sections Pedagogies and Feedback Processes, SDCompetence Application During Internships/Project Work, and Job Position and SD Competences) and interview (section Interview Findings) results are presented and discussed in the next subsections.

\section{Pedagogies and Feedback Processes}

The results on the use of pedagogies to develop SD competences and the required feedback processes to consolidate these competences are depicted in Figure 1, which reports the situation before and during the pandemic emergency. In total 76 students indicated that they attended SD modules before the pandemic, whereas 45 students indicated that they attended SD modules during the pandemic. They were asked to rate their experience of the use of new pedagogies during their academic careers, as

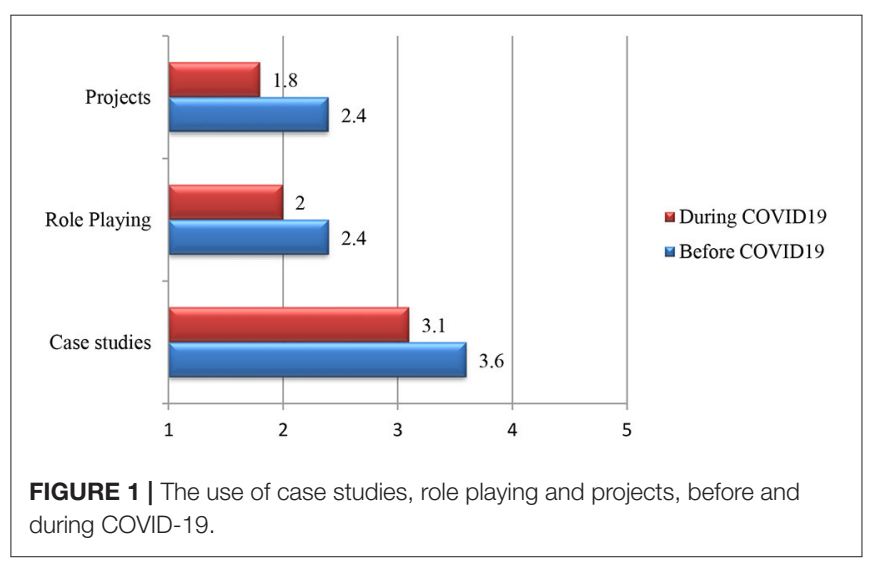


TABLE 2 | The results of the Mann-Whitney $U$ test.

\begin{tabular}{lcccc}
\hline & Case_studies & Role_Playing & Projects & Individual_feedbacks \\
\hline Test statistics & & & & Group_feedbacks \\
Mann-Whitney U & $1,282,000$ & $1,386,000$ & $1,303,000$ & $1,291,500$ \\
Wilcoxon W & $2,317,000$ & $2,421,000$ & $2,338,000$ & $2,326,500$ \\
Z & $-2,397$ & $-1,808$ & $-2,287$ & $-2,352$ \\
Exact sig. [2*(1-tailed Sig.)] & 0.017 & 0.071 & 0.022 & 0.019 \\
\hline
\end{tabular}

Grouping variable: Group (Before COVID-19 vs. during COVID-19).

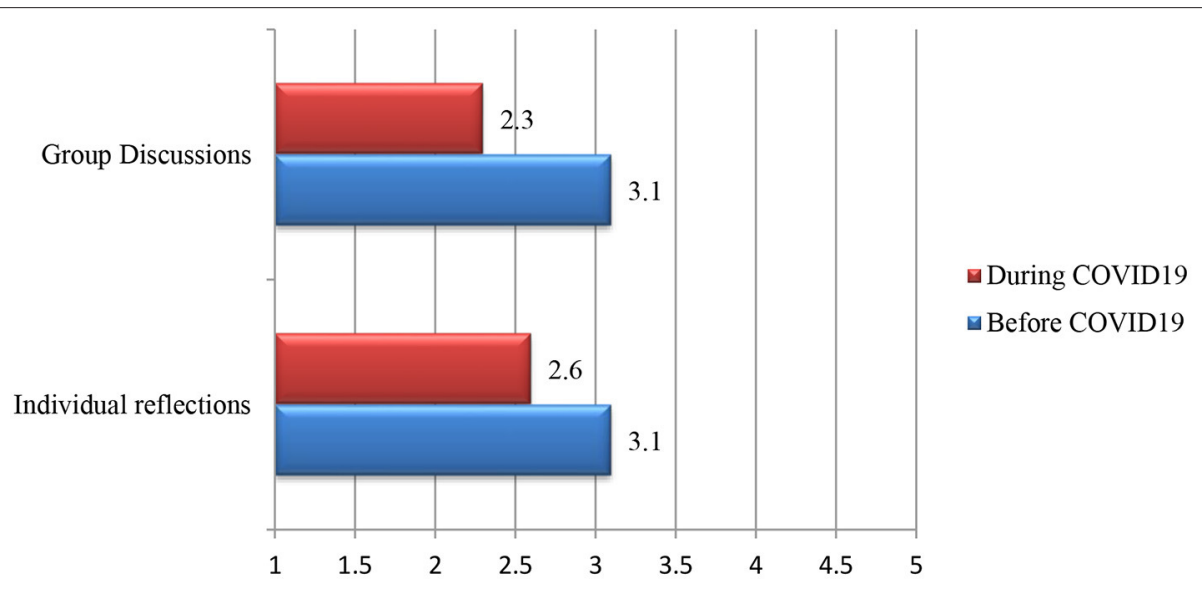

FIGURE 2 | Follow-up sessions (individual or group discussions) before and during COVID-19.

well as the use of follow-up sessions aimed at the development of critical thinking. These sessions could include individual and group reflections on some of the SD topics. The responses of the two previously mentioned samples were analyzed in respect of the students' perception of SD pedagogies and the followup processes.

From the analysis it emerges that before the COVID-19 emergency, students often participated in lectures dealing with case studies, during which they were required to think about SD issues involving different scales, time periods, and domains ( $\mathrm{m}$. \pm st. dev. $=3.6 \pm 0.9$ ). During the pandemic, the use of the case studies approach decreased to a limited extent $(3.1 \pm 1.2)$.

After considering their open-ended role playing that was characterized by interdisciplinary interaction and creative problem solving, the students declared that whereas they sometimes experienced these pedagogies $(2.4 \pm 1.3)$ before the pandemic, they were seldom used during the pandemic $(2 \pm$ 1.1). Furthermore, the students stated that they experienced learning through projects (such as business games) in which they were required to participate in multidisciplinary, multicultural, and international working groups and to interact with external experts and stakeholders to solve sustainability oriented issues before the pandemic $(2.4 \pm 1.3)$ but seldom during the pandemic $(1.8 \pm 1)$. Of the pedagogies used to develop SD competences, only the case studies showed a notable level of application. By contrast, the survey results demonstrate that the use of other pedagogical approaches were not as developed as the
SD-related pedagogies, neither before nor during the COVID19 emergency.

Testing for mean differences, using the Mann-Whitney U Test (Table 2), meaningful differences were detected in the use of SDrelated pedagogical approaches before and after the COVID-19 emergency, especially for case studies and SD projects. The use of case studies decreased ( $p$-value $=0.017$ ), as well as the use of SD projects $(p$-value $=0.022$ ).

As can be noticed from Figure 2, the students experienced follow-up sessions before the pandemic $(3.1 \pm 1.1)$ and also during the pandemic emergency $(2.6 \pm 1.2)$.

The Mann-Whitney U Test confirmed a meaningful decrease of follow-up sessions after the outbreak of the pandemic (Table 2).

\section{SD-Competence Application During Internships/Project Work}

The results on the SD competences developed and applied through internships and project work are presented in Figure 3. Twelve respondents declared that they did SD-related internships or project work.

Students perceived that the internships and project work presented an opportunity to create learning communities through networking and teamwork activities, promoted on behalf of the organization that hosted the internship. Learning communities, in particular, were regarded as a source of new $\mathrm{SD}$ competences $(3.3 \pm 1.1)$. Internships and project work 


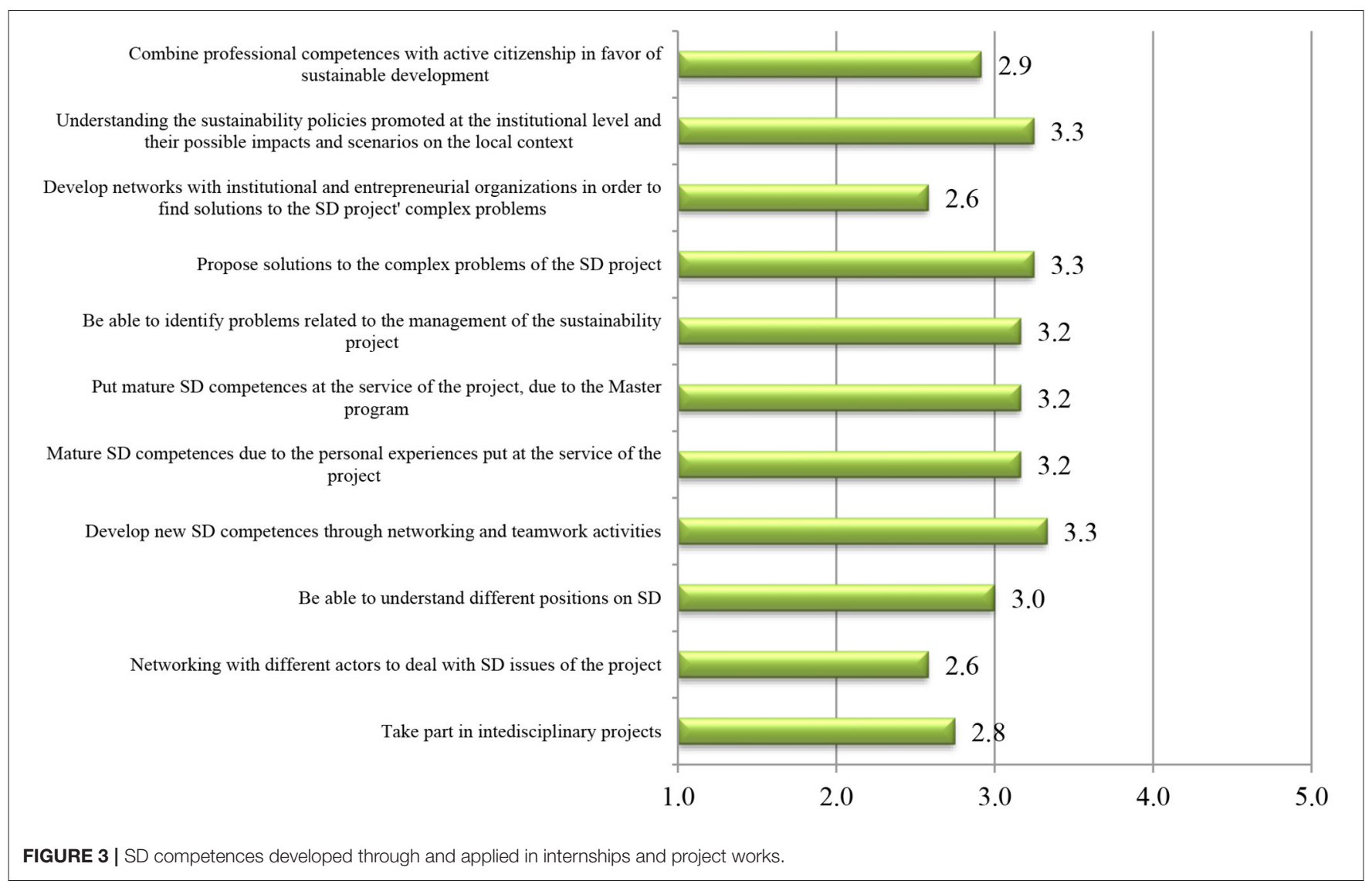

were also deemed to provide a suitable environment to practice skills matured during their academic careers $(3.2 \pm 0.7)$ and to apply personal experiences $(3.2 \pm 0.8)$. Among the competences developed through internships, the ability to propose solutions to complex problems of the relevant project $(3.3 \pm 0.9)$, the ability to better understand sustainability policies promoted at the institutional level and their possible impact on scenario creation in the local context $(3.3 \pm 1.1)$, and the ability to identify problems related to the management of the SD projects $(3.2 \pm 1.2)$ are of particular note. Students rated their participation in projects where the interdisciplinary dimension was addressed through the interaction of different disciplines as quite moderate $(2.8 \pm 1.2)$, and similarly rated the combination of professional competences and active citizenship $(2.9 \pm 1)$. Other competences, such as the development of networks with stakeholders during the internships $(2.6 \pm 1.4)$ and of networks to find shared solutions to the complex problems that emerged during the internships $(2.6 \pm 1.1)$, were rated between slight and moderate.

\section{Job Position and SD Competences}

Regarding their job position, nine students declared that they were employed in a sustainability field at the time of the survey. Their SD-related tasks mainly concerned sustainability reporting, circular economy, and sustainability innovation strategies, as well as the SD of rural and urban areas. The main survey results on the perception of the development and application of SD competences are presented in Figure 4.

Students declared that they foresee the possibility of putting SD competences at the service of their allotted job tasks, in particular SD competences that were developed due to their enrolment and participation in the Master's Programme $(3.3 \pm 1)$. Sustainable development competences developed through personal experiences were also moderately applied in work activities ( $3 \pm 1.2)$, as well as competences developed through teamwork activities (3 $\pm 1.2)$.

Students perceived to have moderately developed the ability to identify SD problems related to their allotted tasks $(3 \pm 1.2)$ and to find solutions to complex work-related SD problems $(3.1 \pm 1.3)$. They furthermore rated their ability to participate in interdisciplinary projects $(2.9 \pm 1.11)$, to network $(2.7 \pm 1)$ in order to find shared solutions to complex work-related SD problems $(2.8 \pm 1.2)$, and to combine professional development with active citizenship $(2.2 \pm 1.4)$ between slight and moderate.

\section{Interview Findings}

Themes and sub-themes emerging from the content analysis of the interviews and the major findings for each theme are reported in Table 3.

The themes are discussed in detail, as follows: 


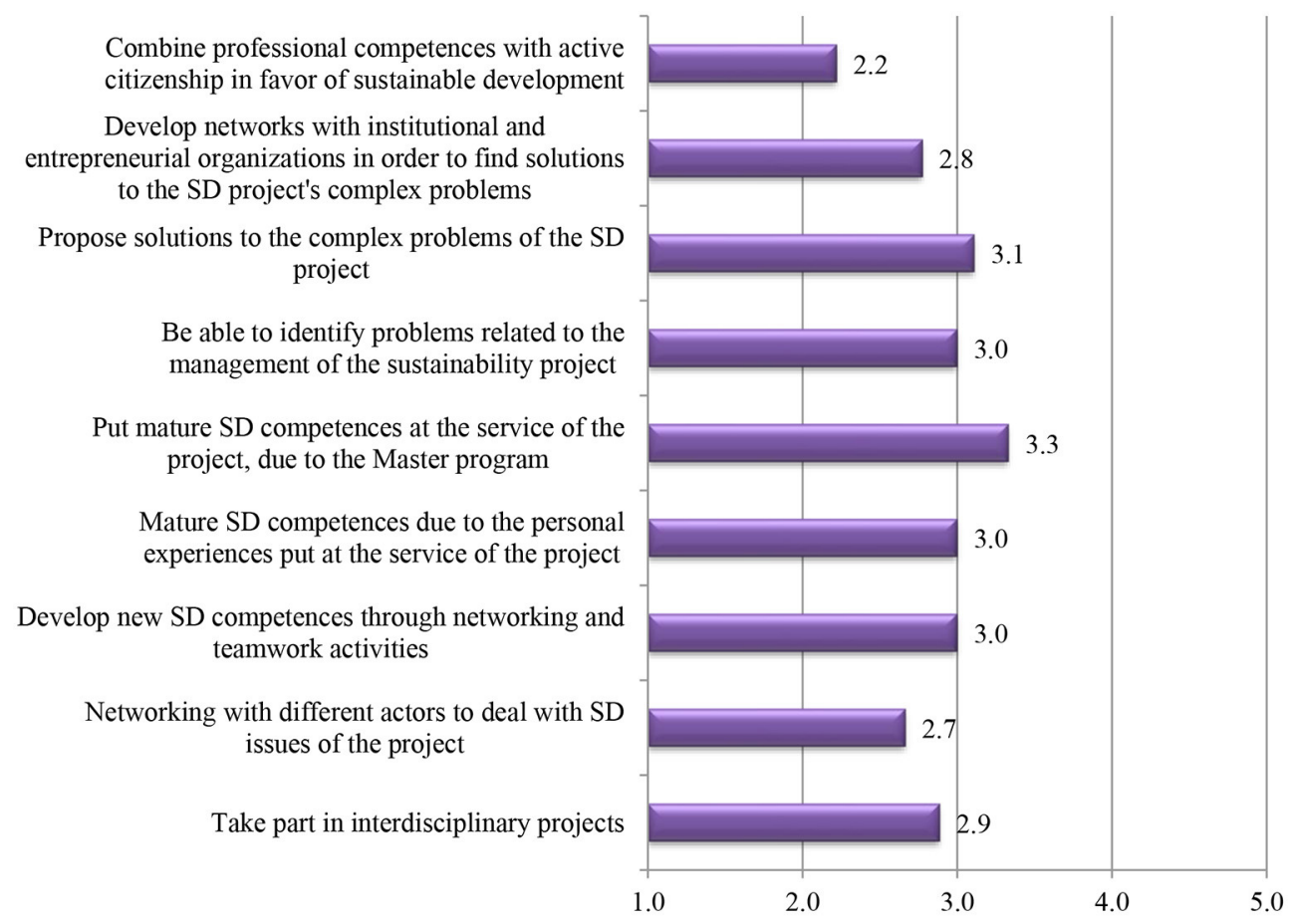

FIGURE 4 | SD competences developed through and applied in the job situation.

\section{SD Pedagogies}

Sustainable development pedagogies were analyzed based on two major sub-themes: (a) students' assessment of SD pedagogies and (b) pedagogies before and during the COVID-19 emergency.

\section{(a) Students' Assessment of SD Pedagogies}

Interviewees experienced case study methodologies that were generally perceived useful to discuss the operationalization of sustainability in business management, and that involved interactions with the teacher and other students, allowing them to share thoughts and visions on $\mathrm{SD}$ in line with a collective learning approach. The implementation of case studies followed a common pattern, involving a discussion of the case study or project (on an individual or teamwork basis) and a subsequent classroom discussion to share ideas on the deepened SD topics. Owing to the case studies, the majority of the students believed that-through interacting activitiesthey had improved their teamwork abilities and had a better understanding of the complexity of sustainability issues and the need to be creative. Indeed, depending on the students' different cultural backgrounds and their personal experiences, interaction allowed an exchange of different opinions on and solutions to SD problems:

\footnotetext{
"The interaction helps to bring out more points of view. I remember a case study carried out in the classroom where I collaborated with some students who came from different cultural backgrounds and who had very different ideas on sustainability than mine. If we talk about the environment and we talk about innovation applied to the
}

environment, innovation is discussion by definition, so interaction is useful because it stimulates creativity" (I8).

Despite this opinion, interviewees nevertheless emphasized the need to increase the number of case studies - the use of which was still considered to be limited-and to customize the case studies' plots based on their personal sustainability interests in order to increase the attractiveness of these pedagogies. Indeed, when case studies were problem based, an interviewee expressed the difficulty of developing critical thinking to this end:

"Case studies I did at other universities-compared to this master's programme-presented a general plot on which each student could work by reconciling the case study with his/her sustainability interests. This approach prioritized discussion with others and allowed me to develop critical thinking. On the contrary, if case studies based on problem solving are provided, based on the material which is already prepared by the teacher, discussion is already 'packed"' (I3).

Opportunities to involve stakeholders through pedagogies-such as case studies, seminars, and workshops-remained limited despite the students' perceived need to increase the kind and number of interactions:

"I think we can add some more practical experience in the curriculum to educate the students (on) SD. When I followed the master's programme, I noticed that my friends and I were interested in sustainable development, but sometimes it's difficult to imagine case studies in practice. During lectures, we learned theory through 
TABLE 3 | Themes, sub-themes, and findings of the interviews' content analysis.

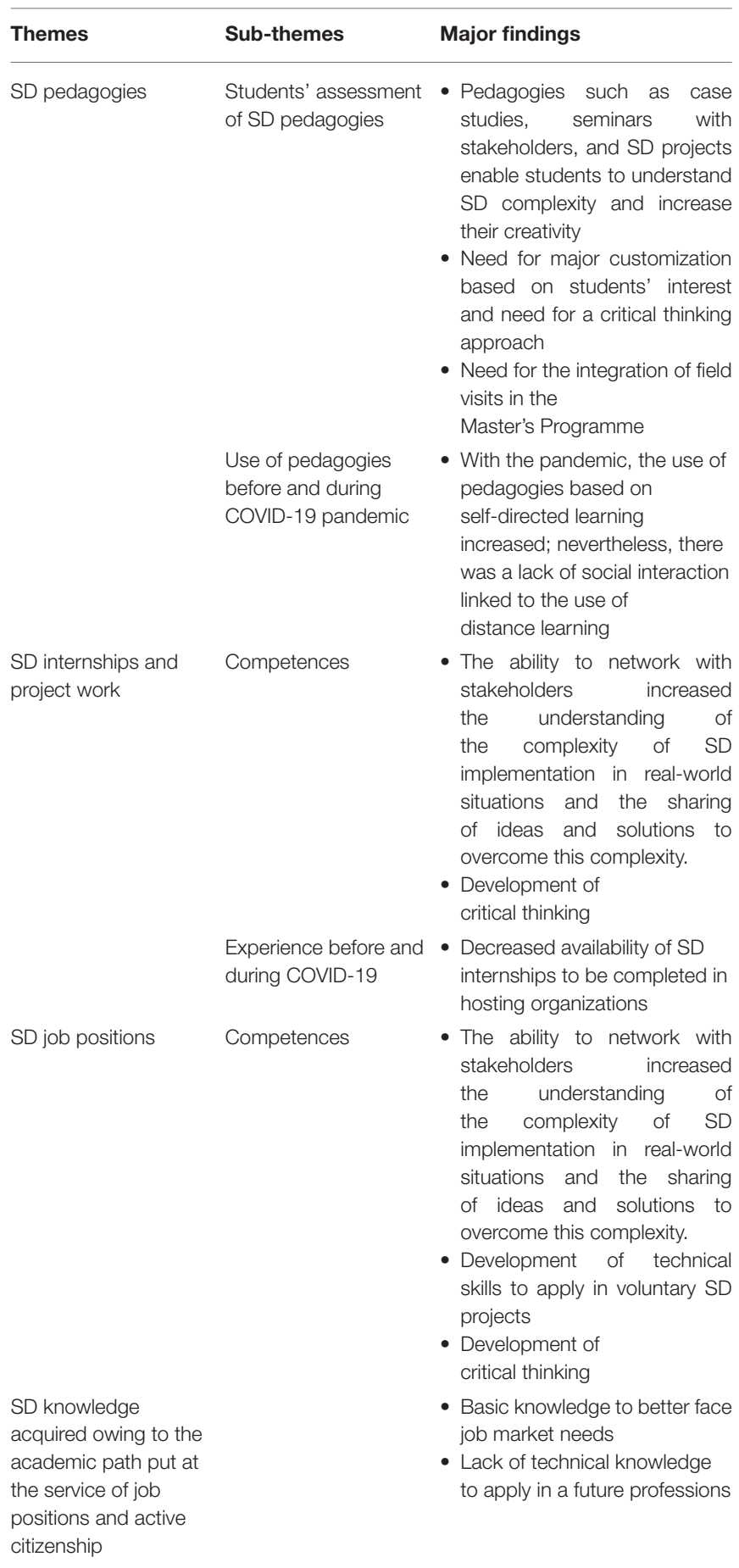

case studies. Nevertheless, we interacted only with the professor. As students, we need to share opinions and ideas with the real market players (industry, government, or even small stakeholders). For example, when we do a field visit, we can interact with the members that are involved in an SD project and we can analyze what is happening based on our academic knowledge. Once I did it for a program's module, mainly through interviews with a small

company; the interaction was very simple but useful. I think it was nice to learn how to conduct interviews, how to undertake a survey and, in general, how to learn to conduct research on a business organization. However, it should not be sporadic and it should find more application" (I4).

The students also experienced SD projects. Some projects were oriented toward self-directed learning as they favored students' autonomy, by deepening topics related to sustainability, and increased their research competences, whereas others were based on team work around a SD topic. Regarding the SD projects, more field experiences were proposed in order to develop a greater knowledge of how the design and implementation of $\mathrm{SD}$ projects work in practice; this aspect was emphasized by an interviewee who compared the Italian master's programme with a Japanese programme that was followed as part of the Erasmus program:

\begin{abstract}
"When I was in Italy, the focus to learn about sustainability was mainly from theory (books, and articles), some of them were case studies (but still in the class) and some were papers/reports I wrote for the professor. Nevertheless, when I was in Japan, the University' department organized a field visit: for example, by meeting and interacting with farmers we learnt about the production of typical rice drinks, starting with the cultivation of rice" (I4).
\end{abstract}

\section{(b) Pedagogies Before and During COVID-19}

As perceived by the interviewees, the use of case studies during the pandemic decreased and provided space for self-directed learning with a critical focus through individual assignments. Students recognized that the pandemic posed a challenge to SD pedagogies characterized by group discussions. In this regard, students admitted that despite the greater space for autonomous research, this development only provided a few opportunities to follow up on self-directed projects. In some modules, even during the pandemic, the teaching involved projects based on teamwork. However, the interviewees perceived these projects as least satisfactory. Furthermore, there was an increase in the opportunity for students to participate in virtual events organized with stakeholders (for instance, virtual conferences, seminars, and workshops). Despite insufficient social interaction in virtual events, because of the limitations of IT support, students deemed their participation in these events as extremely useful. The events were seen as a way of exchanging ideas with experts that otherwise would not have been possible at traditional conferences, because of geographical distances, and as a way to develop technical knowledge and critical thinking on SD topics:

\footnotetext{
"I have not had the opportunity to see stakeholders' involvement during lectures of the two modules of the master's programme I attended before the pandemic. However, if a person is curious and sensitive to these issues, he/she can attend conferences organized by the university. With the pandemic these opportunities have exponentially increased. Almost every day I can, in fact, select conferences to follow and connect with different sustainability experts (from the international to the national and local levels). What is missing is the interpersonal relationship" (I7).
} 
"Also, think about the possibility professors have to share a link to an online streaming event. I can follow the event, understand what is the sustainability perspective of the professor, and we can exchange ideas that deepen the topic" (I8).

Sometimes, students' personal curiosity also served as a stimulus for extensive interactions with professors in order to deepen the SD concepts used during lectures. The students also regarded the possibility of providing recordings of the events as extremely useful, especially as these events increased their absorptive capacity:

\begin{abstract}
"If the event is recorded, I can follow it many times and try to deepen concepts that were discussed, also through personal research. it helps me to better assimilate SD concepts" (i8).
\end{abstract}

Major criticalities of the creation of common SD projects were identified as a result of the transition toward distance learning. These criticalities were linked to the lack of interaction among students, among students and professors, and among students and stakeholders. As argued by an interviewee:

\begin{abstract}
"The fact that there is a lack of social interaction-even with other students-also prevents me from being able to develop ideas for my professional future, for example, opening a consultancy business with colleagues who share the same interest in sustainability" (I7)

"I noticed that in the COVID period, during virtual conferences, occasions for a researcher to search for and develop collaborations on the design of eventual SD projects decreased ... moreover, the information technologies supporting virtual events are still not adequate to promote interaction among people" (I1).
\end{abstract}

\section{Internships and Project Work on SD}

Sustainable development internship and project work were mainly discussed with reference to the following sub-themes: (c) SD competences developed in internship and project work, and (d) COVID-19's impact on SD internships and project work.

\section{(c) SD Competences Matured in Internships/Project Work}

When asked about their perception of competences developed due to the SD internships or project work, interviewees mainly identified the ability to network with stakeholders as a platform to better understand the complexity of sustainability issues in practice and to share ideas and solutions to overcome this complexity. Collective learning took place through extensive interactions with project stakeholders. The interviewees also perceived SD-based internships and project work as a means to better understand the context of sustainability and its implications when implemented in different contexts. When discussing the implementation of sustainability in realworld situations, the interviewees admitted that they found it difficult to apply in practice what they had learnt in the lectures:

"Dealing with the internship on SD gave rise to a very critical thought in myself. When you find a big discrepancy between what you know (theory) and what is put into practice by organizations, it's a bit unsettling. You realize that in order to reach full sustainability, there is still a long way to go... for example, I'm very critical of the auditing processes used by companies to certify sustainability as these processes are not always transparent and effective" (I2)

\section{(d) The Impact of COVID-19 on SD Internships and} Project Work

Internships And project work in organizations such as companies and public institutions became less viable during the pandemic, resulting in the prioritization of smart-working research internships. In terms of impact, some interviewees perceived to have increased their research competences thanks to the research internship, for instance their ability to analyze the impact of different sustainability policies from a decision-making perspective (I10). On the contrary, research internships did not provide access to professional knowledge that otherwise would be accessible in physical SD internships and project work.

Some interviewees also believed that many of the organizations, especially businesses that could be or were involved in SD projects, prioritize other issues during the pandemic, thereby sidelining environmental and social sustainability by giving preference to financial sustainability. An interviewee, who had the opportunity to conduct a project in the field of sustainability reporting, indicated that the pandemic slowed down the development of the project, thereby impeding its eventual completion.

\section{SD Job Positions}

The interviewees described the sustainability related tasks as being characterized by networking activities that, in turn, were deemed useful as a platform to share ideas on the designing of SD projects:

"Surely, being faced with the first job experience, you are faced with a completely new situation that you have not had the opportunity to see while studying. So, working with different stakeholders in this research, I learned to appreciate several points of view on SD. I learned a lot, especially how to manage such complexity" (I3).

The analysis of sustainability in different countries was perceived to involve fundamental elements, specifically culture, policies, and environmental aspects, that have to be considered when proposing and exploiting solutions to SD problems in different local contexts. An interviewee who worked on a field project of sustainable agriculture involving three different countries argued:

"We found that the way to solve SD problems is quite different in different countries because of climate differences, different habits of the stakeholders, different farmers' knowledge on innovations related to sustainable farming, different habits of the stakeholders, etc." (I4).

Sometimes the technical knowledge acquired through workrelated tasks was applied in voluntary projects that were initiated by interviewees because of a personal sensitivity to and interest in SD. Technical skills were thus a prerogative of professional 
development through learning by doing. Critical thinking was also identified as an important competence when considering the difference between the theory provided by university courses and the practice of real-world situations.

An interviewee also indicated that the job-related tasks, along with the knowledge obtained during the master's programme, were particularly useful to develop the ability to anticipate changes linked to sustainability (I6). In particular, the interviewee referred to the ability to analyze the market context in terms of sustainability sensitiveness and to identify ad hoc strategies.

\section{Knowledge Acquired Along the Academic Path and the Application Thereof in Jobs and Active Citizenship}

As a major benefit of the academic path, the interviewees admitted that SD-related education within the Master's Programme was useful as it provided a basic knowledge on sustainability, for instance on sustainability strategies that can be applied in practice from a local to a global level (I5). Some of the interviewees argued that the university's mission is to provide students with critical thinking and tools that can help them face the complexity of the job market, thereby-as students-recognizing the value added to their academic paths:

\begin{abstract}
"University gives you the tools you will need to acquire professionalism in the future job market. Among these tools is the acquisition of critical thinking" (I1).

"I believe that the university should teach the student to learn. Once you realize this, you can apply the method you have learnt to many professions. It would be foolish to think that the university should train us for a job that presumably may no longer exist in the next twenty years" (I2).
\end{abstract}

By contrast, the perception of some interviewees was that the academic path should cover the gaps between theory and practice, thereby promoting more practical activities and projects in the sustainability curricula through a greater dialogue with stakeholders:

\section{"The possibility to involve different stakeholders can be an occasion to see what they really do in practice and show their experiences in terms of sustainability" (I9).}

In this regard, one of the interviewees called for the customization of internships in order to provide more technical skills that can be useful in a future profession.

In addition, knowledge developed along the academic path and personal sensitivity to SD led to the inception of new projects with business organizations and public institutions, for instance in the field of active citizenship. In other cases, it enhanced students' awareness of SD topics:

\footnotetext{
"Some initiatives, I participate in, have emerged thanks to networking abilities matured during (my) academic path. For example, based on the expertise I developed over time, I was contacted by the municipality to create an observation forum
}

to discuss sustainability issues related to the local territory. The observatory serves as a space to disseminate and exchange ideas to solve SD problems" (I7).

The interviewees also regarded knowledge on and personal sensitivity to SD as levers that induce more sustainable behavior (e.g., changing purchasing behavior to avoid waste, green city farming, etc.). At the opposite end, some interviewees chose the Master's Programme with a strong SD focus because of their personal sensitivity to the SD topic.

\section{DISCUSSIONS AND CONCLUSIONS}

This paper involved a case study of an HEI's reorientation of its Master's Programme in Economics and Management to allow students develop mature sustainability competences as learning outcomes. The study fills the gap identified in the literature about the need for research to analyze the effectiveness of pedagogies on students' acquisition of SD competences, and to analyze these pedagogies and competences in the light of the COVID-19 pandemic (Dziubaniuk and Nyholm, 2020). In this study, a constructivist approach was used to analyze the pedagogies implemented by the university under investigation (De Kraker et al., 2007; Kalamas Hedden et al., 2017; Vintere, 2018; Wilhelm et al., 2019; Dziubaniuk and Nyholm, 2020); pedagogies that emphasize social interaction and an interdisciplinary approach as indispensable elements of the understanding of SD topics and the development of students' SD competences.

Owing to an academic path routed toward sustainability and personal experience, the students perceived to have matured SD competences that they could put at the service of the SDrelated tasks and projects they participated in during their internships and employment activities. In addition, the students regarded the internship and work environments as learning environments where the interaction, networking, and team activities with stakeholders assisted them in developing SD competences, despite the university's enhancement of these networking possibilities. This viewpoint corresponds with what is referred to as a "learning community as a learning environment" in which collective learning can assist students to mature and establish SD-related knowledge in different cultural, social, and economic contexts, and to translate this knowledge into practical actions for a more sustainable society (Wilson et al., 2011; Pérez Salgado et al., 2012).

The new pedagogies to develop SD competences were mainly linked to the use of case studies dealing with different knowledge domains, scales (micro, meso, and macro), and time periods (short-term vs. long-term periods). In general, scholars considered this approach to be promising when introducing the complexity of SD problems, as it allows and facilitates students to develop problem-solving abilities (Molderez and Fonseca, 2018). It was shown that case studies represent a diffused approach to teach SD; however, case studies may not be a suitable approach to develop SD competences regarding ethics and responsibility (Lozano et al., 2019). From the perspective of students, case studies based on teamwork and group discussions 
can contribute to an enrichment of their understanding of the complexity of SD issues through a collective learning process (Dziubaniuk and Nyholm, 2020), and are useful to operationalize theoretical knowledge on sustainability strategy implementation in business cases. However, students also recognized the need to increase the use of these pedagogies, to customize case studies in order to develop critical thinking, and to add some practical interaction with stakeholders in order to determine how theoretical knowledge can be applied in practice. In this paper, the developed SD competences were also examined with reference to other pedagogies, including role-playing and projects which emphasized the heterogeneity of participants as an essential component. The examined case study confirmed that these alternative pedagogies are currently insufficiently diffused. Nevertheless, a variety of methods proved to benefit the development of a wide range of SD competences, as different teaching methods-with reference to learning outcomes-tend to complement one another (Lozano et al., 2017). From the interviewees' point of view, and to cover the gap between theory and practice, SD projects should be based more on field experiences, so that teaching and learning can be connected to everyday life (Vintere, 2018). Internships and project work, in particular, covered this gap and students perceived to have had developed critical thinking that allow them to face real-world situations. Research competences were also acquired by students who followed a research internship on the behalf of the university. This modality was incentivized to compensate for the decreased availability of hosting organizations, due to the pandemic. In line with (Lambrechts and Van Petegem, 2016) and owing to the academic path of the Master's Programme, research competences integrate matured SD competences. By focusing on SD job positions, collective learning processes through networking with stakeholders were identified as a means to develop problemsolving abilities for complex sustainability problems. Knowledge developed along the academic path and personal sensitivity were identified as major levers of SD-related tasks, active citizenship' projects, and the adoption of sustainable lifestyles. In this respect, new pedagogies are effective when they initiate personal change toward SD (Wilhelm et al., 2019). Thanks to the modules of the Master's Programme and the internships and project work, the students regard critical thinking as the main ability they have developed.

The pandemic did not provide an opportunity to increase the level of experimentation involving new teaching approaches, such as case studies and projects in a virtual setting. On the contrary, the use of these methodologies decreased with the pandemic, thereby providing space for self-directed learning through autonomous projects. In this case, autonomous research was prioritized despite some opportunities to interact with other students and professors during lectures. The students perceived self-directed learning through personal assignments as a way to deepen sustainability topics; as Dziubaniuk and Nyholm (2020) argue, learning by-doing through personal assignments enables students to approach sustainability in practical terms.
Nevertheless, spurred on by collective learning processes during the pandemic, these approaches alone could not guarantee the acquisition of SD competences. The students regarded virtual settings as an opportunity because they increased the number of conferences, seminars, and workshops that could be accessed during the pandemic, thereby providing them with new technical knowledge obtained from experts and through critical thinking. By contrast, the absence of social interactions was perceived as the major challenge to the use of e-learning, as the opportunity to share ideas and projects was restricted by the limitations of IT support. Given the benefits of the virtual mobility settings for SD education discussed in the literature (Lansu et al., 2010; Pérez Salgado et al., 2012; Barth and Burandt, 2013), it is hoped that universities will further exploit them, being forced by the pandemic to migrate their teaching and research activities online. Indeed, new learning environments present opportunities to create networks that can generate learning communities as a lever to ensure the transition toward SD.

Admittedly, the limitations of the study reside in the analysis of a small sample of students who are completing an SD internship or are working in the SD field, and in the limited samples used to compare the use of SD pedagogies before and during the pandemic. Nevertheless, the analysis of students' opinions can be used to identify strategies to reorient SD education in HEIs, and to improve academic programs by including a wide range of teaching solutions which are currently being tested by many HEIs around the world.

\section{DATA AVAILABILITY STATEMENT}

The original contributions presented in the study are included in the article/supplementary material, further inquiries can be directed to the corresponding author/s.

\section{ETHICS STATEMENT}

Ethical review and approval was not required for the study on human participants in accordance with the local legislation and institutional requirements. Written informed consent for participation was not required for this study in accordance with the national legislation and the institutional requirements.

\section{AUTHOR CONTRIBUTIONS}

The author of the paper is the sole responsible for all the phases of the manuscript's preparation, including the study's conceptualization, methodology, formal analysis, investigation, data curation, and writing.

\section{ACKNOWLEDGMENTS}

The author thanks all the students who participated in the survey and in the interview process. 


\section{REFERENCES}

Azeiteiro, U. M., Bacelar-Nicolau, P., Caetano, F. J., and Caeiro, S. (2015). Education for sustainable development through e-learning in higher education: experiences from Portugal. J. Clean. Prod. 106, 308-319. doi: 10.1016/j.jclepro.2014.11.056

Barth, M., and Burandt, S. (2013). Adding the "e-" to learning for sustainable development: challenges and innovation. Sustainability 5, 2609-2622. doi: $10.3390 /$ su5062609

Bognar, B., Gajger, V., and Ivić, V. (2016). Constructivist e-learning in higher education. Croat. J. Educ. 18(Sp. Ed. 1), 31-46. doi: 10.15516/cje.v18i1.1475

Caniglia, G., John, B., Bellina, L., Lang, D. J., Wiek, A., Cohmer, S., et al. (2018). The glocal curriculum: a model for transnational collaboration in higher education for sustainable development. J. Clean. Prod. 171, 368-376. doi: 10.1016/j.jclepro.2017.09.207

Cebrián, G., and Junyent, M. (2015). Competencies in education for sustainable development: exploring the student teachers' views. Sustainability 7 , 2768-2786. doi: 10.3390/su7032768

Cörvers, R., Wiek, A., De Kraker, J., Lang, D. J., and Martens, P. (2016), “Problembased and project-based learning for sustainable development," in Sustainability Science, eds H. Heinrichs, P. Martens, G. Michelsen, and A. Wiek (Dordrecht: Springer), 349-358. doi: 10.1007/978-94-017-7242-6_29

Crawford, J., Butler-Henderson, K., Rudolph, J., Malkawi, B., Glowatz, M., Burton, R., et al. (2020). COVID-19: 20 countries' higher education intra-period digital pedagogy responses. J. Appl. Learn. Teach. 3, 1-20. doi: 10.37074/jalt.2020.3.1.7

De Kraker, J., Lansu, A., and van Dam-Mieras, R. (2007). "Competences and competence-based learning for sustainable development," in Crossing Boundaries. Innovative Learning for Sustainable Development in Higher Education, eds J. De Kraker, A. Lansu, and M.C. van Dam-Mieras (Frankfurt am Main: Verlag für Akademische Schriften), 103-114.

Dlouhá, J., Heras, R., Mulà, I., Salgado, F. P., and Henderson, L. (2019). Competences to address sdgs in higher education-a reflection on the equilibrium between systemic and personal approaches to achieve transformative action. Sustainability 11:3664. doi: 10.3390/su11133664

Dziubaniuk, O., and Nyholm, M. (2020). Constructivist approach in teaching sustainability and business ethics: a case study. Int. J. Sustain. High. Educ. 22, 177-197. doi: 10.1108/IJSHE-02-2020-0081

Eisenhardt, K. M. (1989). Building theories from case study research. Acad. Manage. Rev. 14, 532-550. doi: 10.5465/amr.1989.4308385

Etikan, I., Musa, S. A., and Alkassim, R. S. (2016). Comparison of convenience sampling and purposive sampling. Am. J. Theor. Appl. Stat. 5, 1-4. doi: 10.11648/j.ajtas.20160501.11

Field, A. (2009). Discovering Statistics Using SPSS:(and Sex and Drugs and Rock'n'roll, 3rd Edn. London: Sage.

Figueiró, P. S., and Raufflet, E. (2015). Sustainability in higher education: a systematic review with focus on management education. J. Clean. Prod. 106, 22-33. doi: 10.1016/j.jclepro.2015.04.118

Gatti, L., Ulrich, M., and Seele, P. (2019). Education for sustainable development through business simulation games: an exploratory study of sustainability gamification and its effects on students' learning outcomes. J. Clean. Prod. 207, 667-678. doi: 10.1016/j.jclepro.2018.09.130

Kalamas Hedden, M., Worthy, R., Akins, E., Slinger-Friedman, V., and Paul, R. C. (2017). Teaching sustainability using an active learning constructivist approach: discipline-specific case studies in higher education. Sustainability 9:1320. doi: $10.3390 /$ su9081320

Lambrechts, W., Mulà, I., Ceulemans, K., Molderez, I., and Gaeremynck, V, (2013). The integration of competences for sustainable development in higher education: an analysis of bachelor programs in management. J. Clean. Prod. 48, 65-73. doi: 10.1016/j.jclepro.2011.12.034

Lambrechts, W., Paul, W. T., Jacques, A., Walravens, H., Van Liedekerke, L., and Van Petegem, P. (2018). Sustainability segmentation of business students: toward self-regulated development of critical and interpretational competences in a post-truth era. J. Clean. Prod. 202, 561-570. doi: 10.1016/j.jclepro.2018.07.303

Lambrechts, W., and Van Petegem, P. (2016). The interrelations between competences for sustainable development and research competences. Int. J. Sustain. High. Educ. 17, 776-795. doi: 10.1108/IJSHE-03-2015-0060
Lansu, A., Boon, J., Sloep, P., and van Dam-Mieras, R. (2010). "Learning in networks for sustainable development," in Proceedings of the 7th International Conference on Networked Learning NLC2010 (Aalborg), 249-256.

Lansu, A., Boon, J., Sloep, P. B., and van Dam-Mieras, R. (2013). Changing professional demands in sustainable regional development: a curriculum design process to meet transboundary competence. J. Clean Prod. 49, 123-133. doi: 10.1016/j.jclepro.2012.10.019

Le Boterf, G. (2015). Construire les Compétences Individuelles et Collectives, 7th Edn. Paris: Eyrolles.

Lozano, R., Barreiro-Gen, M., Lozano, F. J., and Sammalisto, K. (2019). Teaching sustainability in European higher education institutions: assessing the connections between competences and pedagogical approaches. Sustainability 11:1602. doi: $10.3390 /$ sul1061602

Lozano, R., Merrill, M. Y., Sammalisto, K., Ceulemans, K., and Lozano, F. J. (2017). Connecting competences and pedagogical approaches for sustainable development in higher education: a literature review and framework proposal. Sustainability 9:1889. doi: 10.3390/su9101889

Mochizuki, Y., and Fadeeva, Z. (2010). Competences for sustainable development and sustainability. Int. J. Sustain. High. Educ. 11, 391-403. doi: $10.1108 / 14676371011077603$

Molderez, I., and Fonseca, E. (2018). The efficacy of real-world experiences and service learning for fostering competences for sustainable development in higher education. J. Clean. Prod. 172, 4397-4410. doi: 10.1016/j.jclepro.2017.04.062

Moser, C. A., and Kalton, G. (2017). Survey Methods in Social Investigation. Oxford: Routledge. doi: 10.4324/9781315241999

O'Riordan, T., Jacobs, G., Ramanathan, J., and Bina, O. (2020). Investigating the future role of higher education in creating sustainability transitions. Environ. Sci. Policy Sustain. Dev. 62, 4-15. doi: 10.1080/00139157.2020.1764278

Pérez Salgado, F., De Kraker, J., Boon, J., and Van der Klink, M. (2012). Competences for climate change education in a virtual mobility setting. Int. J. Innov. Sustain. Dev. 6, 53-65. doi: 10.1504/IJISD.2012.046053

Pérez Salgado, F., Wilson, G., and Van der Klink, M. (2014). "Transforming academic knowledge and the concept of lived experience: intervention competence in an international e-learning programme", in E-learning and Education for Sustainability, eds U. M. Azeiteiro, W. Leal Filho, and S. Caeiro (Frankfurt am Main: Peter Lang), 59-69.

Pérez Salgado, P., Abbott, D., and Wilson, G. (2018). Dimensions of professional competences for interventions towards sustainability. Sustain. Sci. 13, 163-177. doi: 10.1007/s11625-017-0439-z

Ploum, L., Blok, V., Lans, T., and Omta, O. (2018). Toward a validated competence framework for sustainable entrepreneurship. Organ. Environ. 31, 113-132. doi: 10.1177/10860266176 97039

Roorda, N. (2010). Sailing on the Winds of Change - The Odyssey to Sustainability of the 10 Universities of Applied Sciences in the Netherlands. Ph.D. Thesis, Maastricht University.

Shephard, K. (2008). Higher education for sustainability: seeking affective learning outcomes. Int. J. Sustain. High. Educ. 9, 87-98. doi: $10.1108 / 14676370810842201$

Tejedor, G., Segalàs, J., Barrón, Á., Fernández-Morilla, M., Fuertes, M. T., Ruiz-Morales, J., et al. (2019). Didactic strategies to promote competencies in sustainability. Sustainability 11:2086. doi: 10.3390/su110 72086

Vintere, A. (2018). A constructivist approach to the teaching of mathematics to boost competences needed for sustainable development. Rural Sustain. Res. 39, 1-7. doi: 10.2478/plua-201 8-0001

Wiek, A., Bernstein, M., Foley, R., Cohen, M., Forrest, N., Kuzdas, C., et al. (2015). "Operationalising competencies in higher education for sustainable development," in Handbook of Higher Education for Sustainable Development, eds M. Barth, G. Michelsen, M. Rieckmann, and I. Thomas (London: Routledge), 241-260.

Wiek, A., Withycombe, L., and Redman, C. L. (2011). Key competencies in sustainability: a reference framework for academic program development. Sustain. Sci. 6, 203-218. doi: 10.1007/s11625-0110132-6 
Wilhelm, S., Förster, R., and Zimmermann, A. B. (2019). Implementing competence orientation: Towards constructively aligned education for sustainable development in university-level teaching-and-learning. Sustainability 11:1891. doi: 10.3390/su110 71891

Wilson, G., Abbott, D., De Kraker, J., Salgado Pérez, P., Scheltinga, C., and Willems, P. (2011). 'The lived experience of climate change': creating open educational resources and virtual mobility for an innovative, integrative and competence-based track at master's level. Int. J. Technol. Enhan. Learn. 3, 111-123. doi: 10.1504/IJTEL.2011.039396
Conflict of Interest: The author declares that the research was conducted in the absence of any commercial or financial relationships that could be construed as a potential conflict of interest.

Copyright $\odot 2021$ Cavicchi. This is an open-access article distributed under the terms of the Creative Commons Attribution License (CC BY). The use, distribution or reproduction in other forums is permitted, provided the original author $(s)$ and the copyright owner(s) are credited and that the original publication in this journal is cited, in accordance with accepted academic practice. No use, distribution or reproduction is permitted which does not comply with these terms. 